\title{
El patrimonio arquitectónico en la comarca de los Pedroches
}

M. ${ }^{\text {a }}$ Mercedes Fernández Martín | Universidad de Sevilla

URL de la contribución <www.iaph.es/revistaph/index.php/revistaph/article/view/3506>

\section{RESUMEN}

La comarca de los Pedroches, dada su trayectoria histórica, conserva interesantes muestras de arquitectura. Entre los ejemplos más significativos está la desarrollada por los Hernán Ruiz, padre e hijo, activos en la comarca durante buena parte del siglo XVI. Asimismo, conserva una interesante arquitectura popular, marcada por la utilización del granito.

\section{Palabras clave}

Arquitectura agraria | Arquitectura popular | Hernán Ruiz, el Viejo | Hernán Ruiz, el Joven | Los Pedroches | Sotomayor y Zúñiga | 


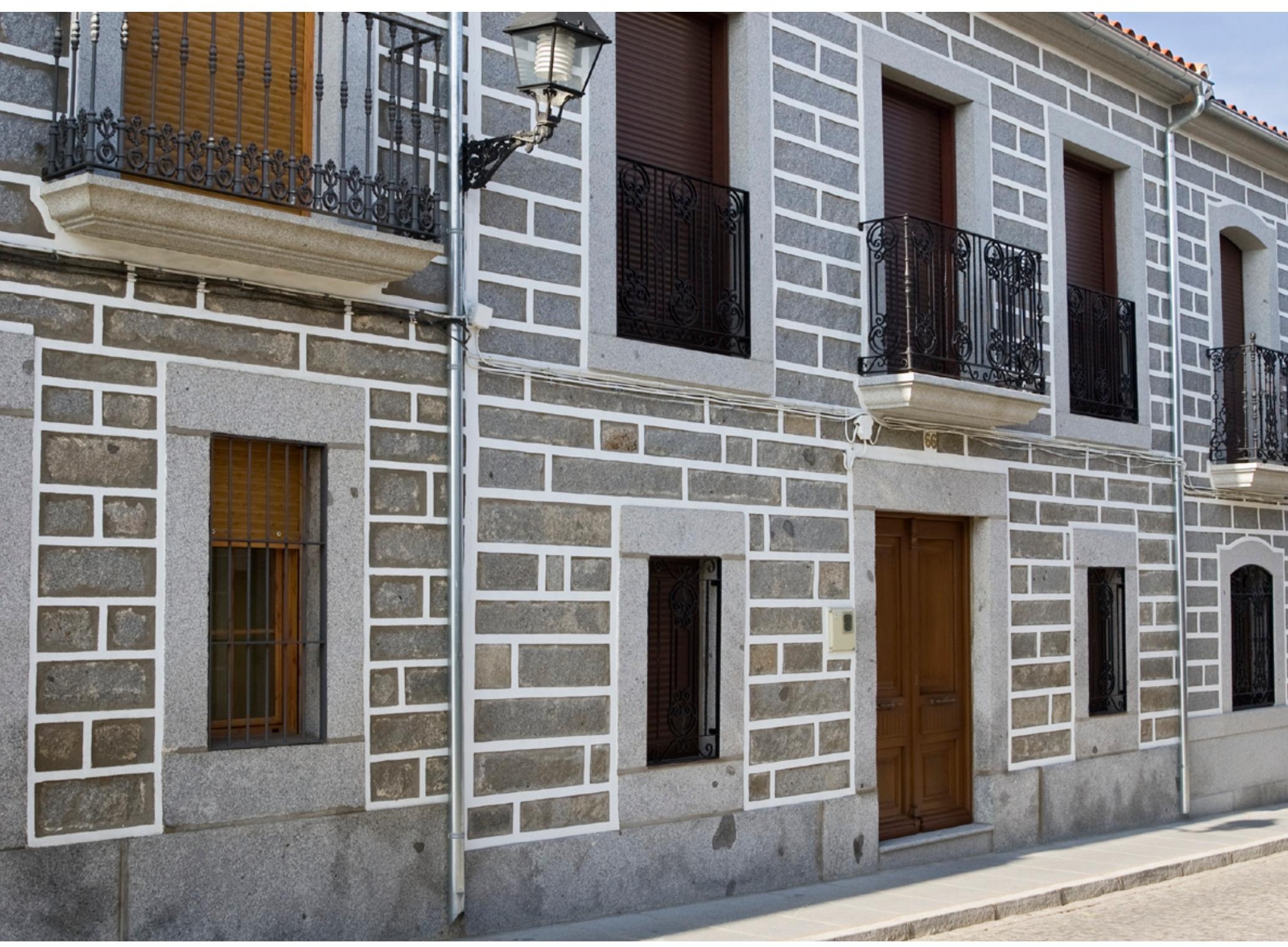

Fachada de granito en Añora | foto Fondo Gráfico IAPH 


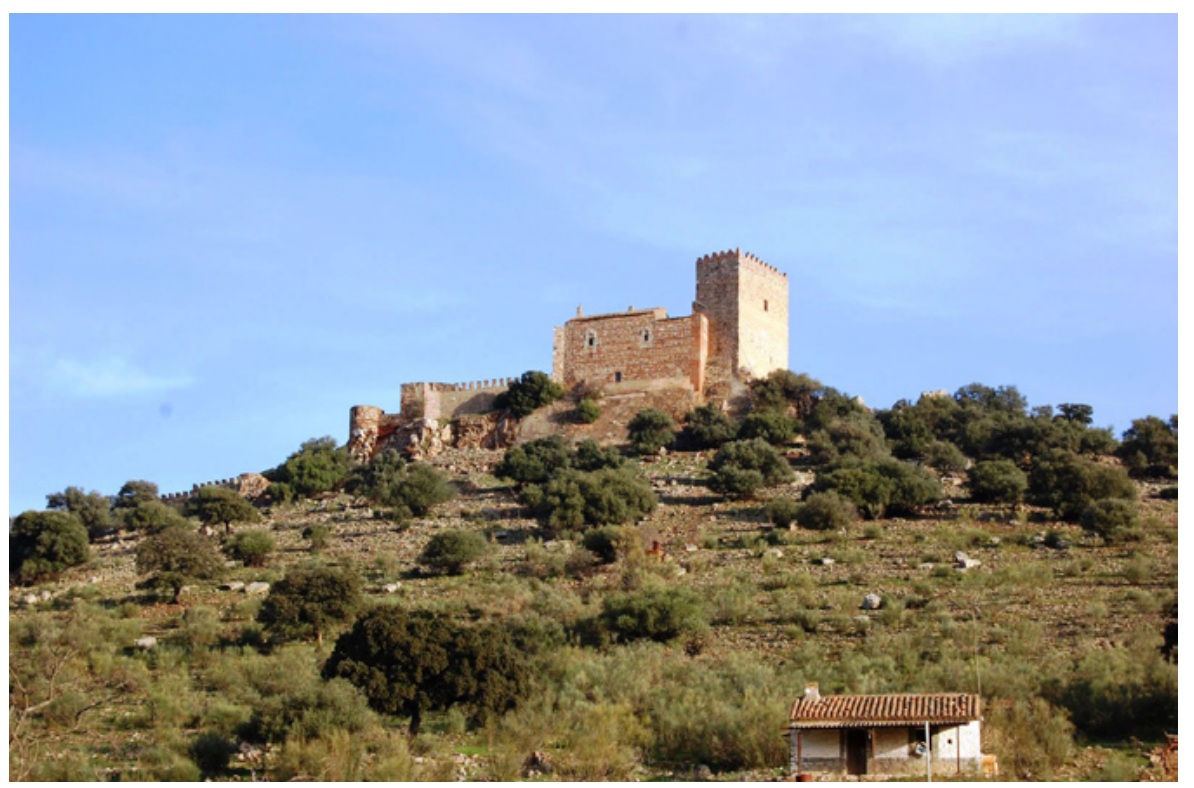

El Viso. Castillo de Madroñiz | fuente VILLAR; DABRIO; RAYA, 2006

Los Pedroches constituyen uno de los más claros ejemplos de comarca natural y una de las más extensas de la provincia de Córdoba, con unas características bien definidas, debido principalmente a su situación geográfica y a sus límites naturales. Situada al norte de la provincia de Córdoba, limita al noroeste con Extremadura, al noreste con la Comunidad Autónoma de Castilla la Mancha, sureste con la provincia de Jaén y por el sur y suroeste con Córdoba.

En la actualidad está integrada por 17 municipios: Alcaracejos, Añora, Belalcázar, Cardeña, Conquista, Dos Torres, El Guijo, Fuente la Lancha, Hinojosa del Duque, Pedroches, Pozoblanco, Santa Eufemia, Torrecampo, Villanueva de Córdoba, Villanueva del Duque, Villaralto y El Viso. Su acusada personalidad está propiciada por la existencia de un zócalo granítico sobre la que se asienta, material que va a marcar significativamente su arquitectura. Tan amplio territorio se puede dividir en dos subcomarcas, que van a propiciar asimismo su evolución histórica. En la subcomarca occidental se establecieron los señoríos de Santa Eufemia y de Belalcázar, mientras que sobre la oriental se constituyó la comunidad de las Siete Villas de los Pedroches, que salvo un período de tiempo, fueron siempre tierras de realengo. Tan dispares características históricas van a influir también en su arquitectura.

Los restos arqueológicos de diversas épocas prehistóricas aparecidos en muchos puntos de su geografía atestiguan el poblamiento de esta comarca desde antiguo, pero fue durante la dominación romana cuando gozó de una gran importancia, debido a su riqueza ganadera y a los minerales de su sub- 
suelo. La conquista árabe fortaleció aún más su tradición ganadera, teniendo sus dos núcleos más importantes en Belalcázar y Pedroche. Tras la reconquista pasó a la autoridad de la Corona, iniciándose el proceso repoblador de la zona y con ello las principales manifestaciones arquitectónicas.

Las construcciones más antiguas que se conservan se deben precisamente al proceso repoblador y están representadas por los castillos de Madroñiz y Belalcázar. El primero, situado sobre un cerro en el término municipal de EI Viso, fue construido por los árabes en los siglos XI o XII. Durante mucho tiempo la importancia de este castillo radicaba en ser la defensa del único camino que llevaba a Toledo, y pertenecer a una red de comunicación y vigilancia junto con otras fortificaciones del norte de la provincia de Córdoba y de las comunidades limítrofes. En el siglo XV pasó a formar parte del señorío de Santa Eufemia, al que ha estado históricamente vinculado. A ese período se debe su reconstrucción, siendo totalmente reformado en los siglos XIX y XX. Por su parte, el castillo de Belalcázar es uno de los monumentos más relevantes de la comarca de Los Pedroches y por tanto merecedor de un estudio individualizado ${ }^{1}$.

Al ser tierra de Reconquista la mayoría de sus pueblos se consolidaron a partir del siglo $\mathrm{XV}$, muchos de los cuales fueron en origen ventas concedidas a Córdoba por Enrique III en el camino real de la Plata, que unía Córdoba con Toledo. A esas fechas se debe la construcción de un considerable número de iglesias y ermitas donde la presencia mudéjar ha dejado su huella. Con frecuencia son construcciones que han sufrido profundas alteraciones, aunque mantienen sus sencillas estructuras y las características propias de la arquitectura vernácula, patrimonio etnográfico, que cada vez cobra más valor.

El período más importante para la arquitectura de la comarca es sin lugar a dudas el de los años finales del siglos XV y el siglo XVI, fecha en que adquiere una gran importancia el señorío de Belalcázar. Durante este período ejerció su patronazgo arquitectónico y artístico don Francisco de Zúñiga Guzmán y Sotomayor, IV conde de Belalcázar, marqués de Ayamonte y III duque de Béjar, con la realización de importantes empresas. En 1466 Alfonso de Sotomayor había levantado el castillo, la principal edificación de la población. No obstante, fue don Francisco de Zúñiga el que le dio un nuevo uso en el primer tercio del siglo XVI, uniendo a su condición de fortaleza la adecuación del edificio a palacio renacentista. Se trata de una obra singular, claramente individualizada del castillo medieval (MOLINERO MERCHÁN, 2011: 315 y ss.).

La nueva construcción se adosó en uno de los costados de la fortaleza medieval proyectada hacia la población. Las fachadas están organizadas en tres cuerpos, mereciendo mayor atención decorativa la parte superior, con una progresiva apertura de vanos. El programa ornamental se circunscribe
El estudio de las fortalezas de Belalcázar ha sido realizado en esta misma publicación por Alberto León Muñoz, al que remito. Al respecto véase también León Muñoz (2003).

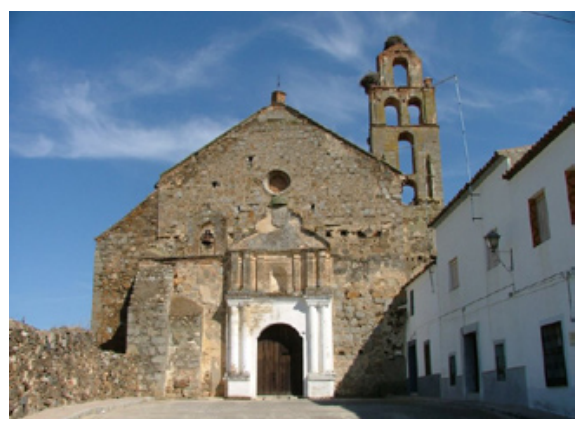

Belalcázar. Convento de los Mártires de Marruecos | fuente VILLAR; DABRIO; RAYA, 2006

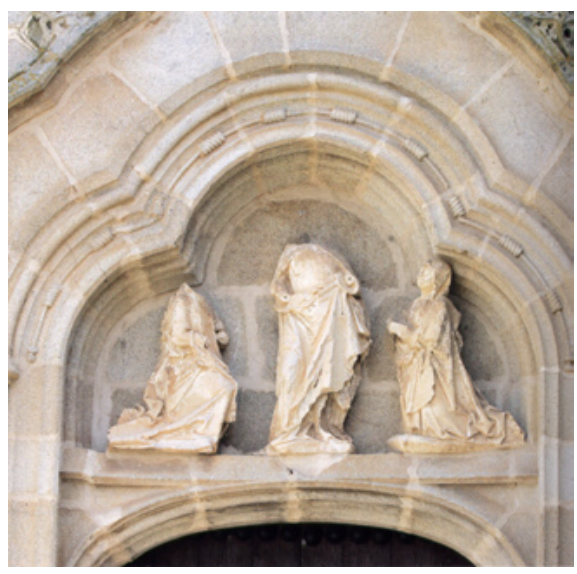

Belalcázar. Convento de Santa Clara de la Columna Siglo XVI | fuente VILLAR; DABRIO; RAYA, 2006 


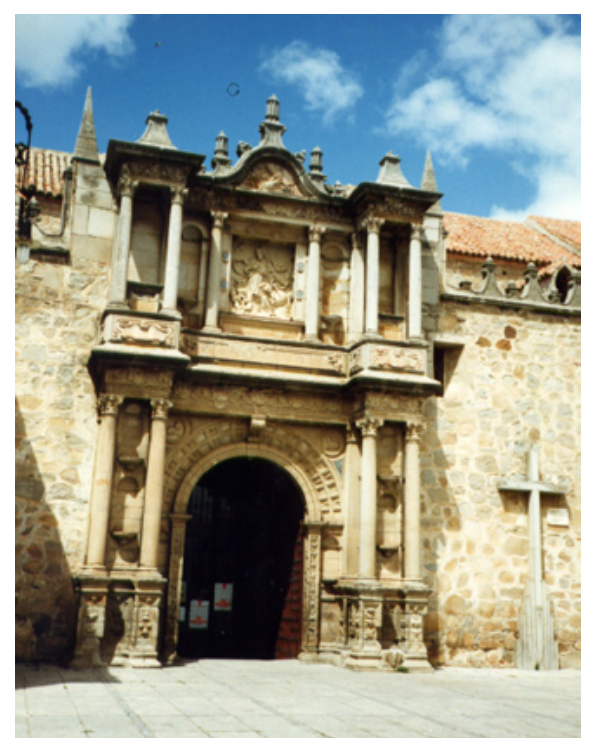

Hinojosa del Duque. Portada de la iglesia de San Juan Bautista | foto Mercedes Fernández Martín

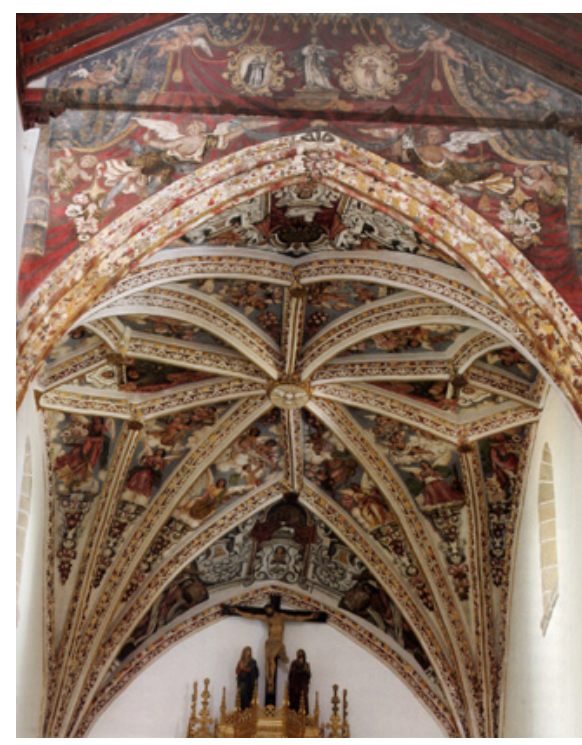

Iglesia parroquial de San Juan Bautista. Hinojosa del Duque | foto Mercedes Fernández Martín al enmarque de las ventanas y del balcón principal, con motivos del repertorio renacentista como tondos, cuernos de la abundancia, flameros, unidos entre sí por motivos en forma de $\mathrm{S}$, delfines vegetalizados enlazados por la cola y escudos heráldicos, modelos similares, aunque de menor calidad a los que decoran las ventanas de la sacristía de la iglesia parroquial de san Juan Bautista de Hinojosa del Duque. Estas similitudes avalan la atribución de la autoría de la obra a Hernán Ruiz el Viejo, aunque probablemente la ejecución material fuera de la mano de otros entalladores.

Los Sotomayor de Belalcázar ejercieron el mismo patronazgo con la fundación de nuevos conventos en la ciudad, como los de santa Clara de la Columna y el de los Cinco Mártires de Marruecos. La iglesia del convento de santa Clara de la Columna se fundó en el último cuarto del siglo XV por iniciativa de doña Elvira de Zúñiga para mausoleo familiar. El proyecto de panteón recayó en los maestros cordobeses Hernán Ruiz I y Sebastián Peñaredonda, si bien quedó sin realizar. Únicamente se labró la portada (MOLINERO MERCHÁN, 2011: 423 y ss.). Aunque ha sufrido una profunda restauración en los últimos años, la iglesia conserva su fisonomía primitiva, con una única nave cubierta con bóvedas estrelladas realzadas con pinturas murales de motivos vegetales, medallones con ángeles y símbolos pasionarios, que se fechan en el siglo XVIII. La fachada de la iglesia presenta una portada de arco carpanel presidido por un grupo escultórico en piedra con la figura de Cristo bendiciendo, flanqueado por la Magdalena y santa Clara. A las tres figuras les falta la cabeza y se pueden fechar en los primeros años del siglo XVI.

También fundación de los duques en la primera mitad del siglo XV es el convento de franciscanos de los santos Mártires de Marruecos, muy alterado en la actualidad. En 1486 se proyectó como panteón funerario para la casa de Sotomayor y en el intervino Hernán Ruiz el Joven, encargado de la construcción de la capilla funeraria de los Vargas (MOLINERO MERCHÁN, 2011: 304; 431 y ss.). Desgraciadamente, el fallecimiento del promotor hizo que no se realizara el programa escultórico. De la riqueza artística que debió tener el edificio primitivo poco queda, sólo vagos vestigios de su arquitectura y decoración renacentista. La portada presenta un arco de medio punto rebajado, enmarcado por gruesas columnas pareadas sobre pedestales. Sobre éste una hornacina con arco de medio punto, flanqueada por pilastras y rematada por frontón partido que alberga el escudo original con las armas de Sotomayor y Enriquez. Por último, también a este patronazgo se debe la construcción de la fuente del Pilar, junto a la fortaleza de Belalcázar, donde se combina la funcionalidad del abrevadero y la monumentalidad arquitectónica de la fuente.

Este patronazgo también se extendió a la cercana ciudad de Hinojosa del Duque, y en concreto a la sacristía de la iglesia parroquial de san Juan Bautista, una de las obras arquitectónicas y escultóricas más importantes 
del Renacimiento de los Pedroches. La iglesia parroquial se había construido en los últimos años del siglo XV, siguiendo modelos del gótico. A partir del segundo tercio de la centuria siguiente el edificio experimentó una total renovación, imprimiéndole sus características renacentistas, encargándose de las obras el maestro Hernán Ruiz, el Viejo. El maestro cordobés se encargó de la construcción de la puerta de la epístola, la capilla bautismal y la sacristía, obras que posteriormente concluiría su hijo Hernán Ruiz, el Joven. En el exterior la sacristía está rematada por una balaustrada de piedra formada por candeleros unidos entre sí por medio de motivos ornamentales en forma de $\mathrm{S}$, disponiéndose bajo la cornisa gárgolas esculpidas también en granito. El programa iconográfico de la misma está basado en la heráldica de la casa de los Sotomayor.

En la misma población los señores de Belalcázar fundaron el convento de la Purísima Concepción, en memoria del fundador del linaje don Gutierre de Sotomayor. El edificio quedó bajo la dirección de la orden franciscana, si bien la obra del convento se prolongó a lo largo del siglo XVII, época en las que se fechan sus portadas, en las que campean los escudos de los Zúñiga y Sotomayor, concluyéndose en 1693.

Sin lugar a dudas la participación más importante de Hernán Ruiz el Joven fue en la iglesia de san Juan Bautista de Hinojosa del Duque, donde campean los escudos nobiliarios de sus fundadores. El Joven va a proseguir las obras iniciadas por su padre, datándose su actuación en 1559, trabajando en la portada meridional del templo, aunque también resulta indudable su participación en la capilla bautismal. Asimismo, se le atribuyó el diseño de la torre-fachada, dato que no se ha podido confirmar documentalmente ${ }^{2}$. La portada se ejecutó entre 1539 y 1571, correspondiendo a la intervención de Hernán Ruiz el Viejo el diseño del vano de ingreso, mientras que a su hijo se debe la decoración del enmarque y todo el cuerpo superior, resuelto con maestría y monumentalidad.

En la capilla bautismal, aunque sin documentar, se aprecia la participación del maestro, tanto en la bóveda como en la ventana. La bóveda vaída está decorada con motivos geométricos, mientras que la ventana es una magistral lección de perspectiva, relacionada con algunas ilustraciones de su Manuscrito (MORALES, 1996: 20). Asimismo, un proyecto suyo pudo servir de base a Juan de Ochoa para trazar la torre-fachada de la iglesia, concluida en 1590, apreciable en la utilización de espejos de cerámica y el uso del hueco serliano. De los tres cuerpos del campanario, rectangular, cuadrado y octogonal, es de destacar el inferior, solucionado como un arco cuadrifronte. Asimismo, se ha querido ver la intervención del maestro y de su aparejador Sebastián de Peñaredonda en la parroquia de Santiago de Belalcázar, edificio con un proceso constructivo bastante complejo (MORALES, 1996: 18).
2

La atribución corresponde a Banda y Vargas (1974: 110). 
Las Siete Villas de Los Pedroches, por su condición de tierras realengas, con el mantenimiento de la comunidad de términos, no tuvo el patronazgo de las villas de señorío. Comprenden los municipios de Pedroche, Dos Torres (Torremilano y Torrefranca), Torrecampo, Pozoblanco, Villanueva de Córdoba, Alcaracejos y Añora. Pedroche constituye el núcleo de la comarca de su nombre y entre sus edificios religiosos sobresale la parroquia del Salvador, una de las construcciones más notables de la provincia de Córdoba. De estilo gótico mudéjar, su construcción data del siglo XVI, realizada posiblemente sobre una antigua mezquita próxima al castillo. El edificio de tres naves se cubre con armaduras de madera, siendo la central de lacería, mientras que la cabecera es de cantería con bóveda de crucería. El interior estuvo decorado con pinturas murales fechables en la primera mitad del siglo XVI de las que sólo quedan unos restos. Desde el punto de vista arquitectónico tiene gran interés su torre renacentista que se eleva, en cuatro cuerpos perfectamente diferenciados, hasta los 56 metros de altura. Fue construida entre 1532 y 1588 y en su construcción participó Hernán Ruiz II, donde incorporó un cuerpo cuadrado muy sobrio, con dos vanos por fachada a otros, cuadrado y poligonal, levantados por sus antecesores al frente de la obra. Con posterioridad a su intervención, entre 1544 y 1558, Juan de Ochoa levantó el cuerpo cilíndrico, que sirve de remate al campanario y que posiblemente también derive de un diseño de Ruiz.

Igualmente, varias iglesias parroquiales y otros templos se fechan entre los últimos años del siglo XV y los primeros de la centuria siguiente. Entre ellas está la iglesia parroquial de Dos Torres, bajo la advocación de Nuestra Señora de la Asunción. Era la iglesia de la antigua Torremilano y tiene su origen en el siglo XV, pero muy reformada en los dos siglos posteriores. Presenta tres naves cubiertas por armadura mudéjar, mientras que el presbiterio lo hace por medio de una bóveda de crucería con trompas angulares. En el lado del evangelio se abre la capilla de la Inmaculada, fundada por Pedro Gómez de Contreras, tesorero de Indias, y construida entre 1585 y 1595, por un maestro local, Bartolomé Hernández, cubierta asimismo con bóveda de crucería. En la nave de la derecha se abre otra capilla, la del Sagrario, que puede fecharse en los últimos años de aquella centuria. De las mismas fechas es también la antigua iglesia, hoy desacralizada, de Torrefranca y que estuvo dedicada a Santiago. Anterior en el tiempo es la iglesia parroquial de Nuestra Señora de la Encarnación de Santa Eufemia, pues sus orígenes se remontan a los años finales del siglo XIV o principios del XV. Responde a la típica disposición de nave única con arcos diafragma, donde abren cuatro capiIlas y una cabecera poligonal cubierta por cuarto de esferas, mientras que el resto lo hace con una armadura de madera que sustituyó a otra con decoración mudéjar, de las que se conservan algunos tableros.

La iglesia parroquial de san Sebastián de Añora fue construida también en el siglo XVI pero sufrió importantes transformaciones en los dos siglos siguien- 
tes. La iglesia de tres naves cubre la central y la capilla mayor con una armadura de madera con tirantes y decoración de lazo. En uno de los tirantes se lee la fecha de 1630. Por su parte, la parroquia de El Guijo, bajo la advocación de san Sebastián fue construida en el siglo XVI pero sufrió importantes transformaciones en los dos siglos siguientes. Similares características presenta la parroquia de san Sebastián de Torrecampo, documentada al menos desde 1550. Responde a modelos mudéjares, de tres naves y triple cabecera plana cubierta con bóveda de crucería.

Otras obras arquitectónicas de gran presencia en la comarca de los Pedroches son las ermitas, tanto las dedicadas a advocaciones marianas como las consagradas a diferentes santos, donde la devoción popular encuentra un amplio eco con un gran número de construcciones de carácter popular. Entre las primeras destaca la de Nuestra Señora de Gracia de Alcantarillas en Belalcázar, que sigue un tipo muy característico, con tres naves y capilla mayor plana, cubierta con bóveda de crucería gótica que se puede fechar a fines del siglo XV o comienzos del XVI. El granito, abundante en la comarca, alternado con la cal, son los materiales empleados e imprime un sello inconfundible a esta arquitectura. Algunos materiales son de acarreo, entre ellos destacan varios capiteles y algunas inscripciones de época romana. Característico de esta ermita, y de otras muchas de este tipo, es el pórtico, que en el caso de la que nos ocupa se extiende por parte de las fachadas laterales. Belalcázar también cuenta con varias ermitas de origen medieval pero muy alteradas donde lo más destacado, en las de nave única como las de san Antón y san Sebastián, son los arcos diafragma, tan frecuentes en la comarca. También de origen mudéjar es la ermita de san Sebastián en Hinojosa del Duque. Su planta presenta la típica disposición de las ermitas serranas, caracterizadas por la simplicidad y funcionalidad de sus elementos arquitectónicos y su sobriedad decorativa. Lo que imprime carácter a esta arquitectura religiosa popular son los grandes arcos diafragma contrarrestados al exterior por contrafuertes.

Otras ermitas son compartidas por varios pueblos como de la Virgen de Luna en Pozoblanco y Villanueva de Córdoba; la Virgen del Camino y de Consolación, veneradas en Belalcázar e Hinojosa del Duque; la Virgen de las Cruces en El Guijo, Torrecampo y Santa Eufemia, cuya ermita se encuentra a pocos kilómetros de la primera que, aunque muy reformada en el siglo $\mathrm{XX}$, en origen corresponde a una construcción del Setecientos. Por último, la ermita de la Virgen de Guía cuyo patronazgo y devoción se extiende a cinco villas, Alcarecejos, Dos Torres, Fuente la Lancha, Hinojosa del Duque y Villanueva del Duque. Se levanta al norte de Villanueva del Duque, muy cerca del núcleo urbano y el edificio actual sustituye a otro anterior mas modesto que data de las primeras décadas del siglo XVI. Su exterior es severo y de gran solidez, del cual sólo son destacables los contrafuertes que rodean el edificio y la fachada principal, totalmente de granito, decorada

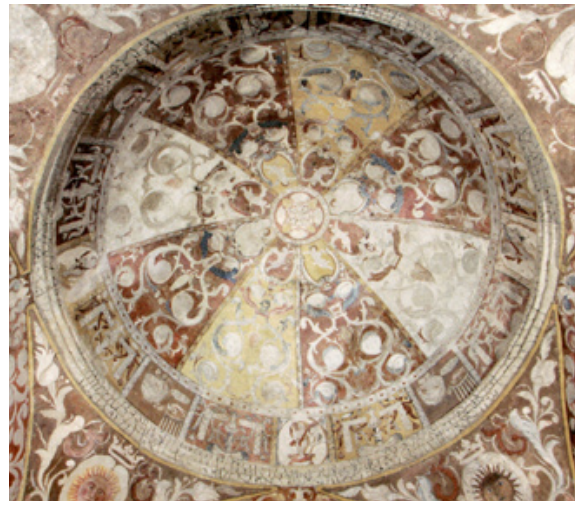

Torrecampo. Ermita de la Virgen de Gracia, s. XVI | fuente VILLAR; DABRIO; RAYA, 2006

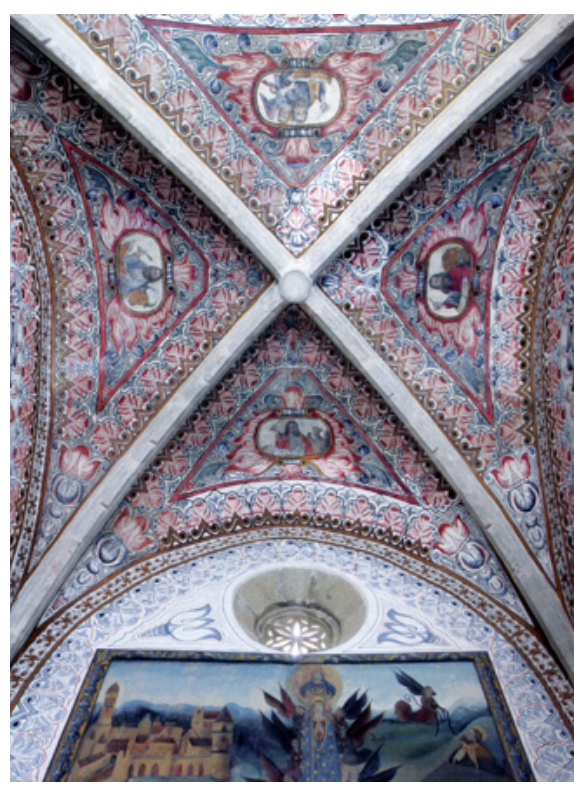

Villanueva del Duque, ermita de Ntra. Sra. de Guía | fuente VILLAR; DABRIO; RAYA, 2006 
con un arco gótico y un rosetón de época tardía. Más interesante resulta la arquitectura del interior, formada por tres naves, separadas por columnas graníticas que sustenta airosos arcos, tres a cada lado, y un púlpito en piedra de 1567. Sin duda es el presbiterio el espacio de mayor mérito artístico, protegido por una reja de 1587, presenta bóveda de crucería y sus muros se encuentran pintados al fresco, restaurados entre 1998 y 2002. Muy deteriorados, sólo la escena frontal puede considerarse original, con escenas de la Asunción y la coronación de la Virgen.

Otras muchas ermitas fueron remodeladas o construidas de nueva planta en el siglo XVII y XVIII, como las de Añora dedicadas a san Pedro, reformada en 1694 y a la patrona, la Virgen de la Peña, construida en el siglo XVIII. Dos Torres cuenta con varias como la de la patrona, Nuestra Señora del Loreto, reconstruida entre 1714 y 1766, si bien la más antigua es la de san Bartolomé, del siglo $\mathrm{XVI}$. En otras ocasiones muchas de estas ermitas fueron reconvertidas en parroquias, como las de san Bartolomé y san Sebastián, ambas en Pozoblanco.

Por otra parte, muchos edificios religiosos se han perdido, reconstruyéndose o levantándose de nueva planta en la segunda mitad del siglo XX. Entre la década de 1950 y 1960 el arquitecto diocesano Carlos Sáenz de Santamaría realizó las parroquias de Cardeña y Conquista, así como la iglesia del Dulce Nombre de Jesús en Villanueva de Córdoba, uno de los edificios más interesantes de ese siglo en la provincia. En otros se han conservado algunos vestigios del primitivo edificio como la iglesia parroquial de Alcaracejos, levantada sobre la antigua en 1965 por el arquitecto Daniel Sánchez Puch. De la antigua fábrica se conserva una portada gótica de granito, labrada en ladrillo con un arco conopial y una decoración tosca, enmarcándose el conjunto por un alfiz a base de pomas o bolas y que puede fecharse en los últimos años del siglo XV.

Frente a la arquitectura religiosa, la comarca de los Pedroches cuenta con una interesante arquitectura popular de gran originalidad, con su caserío de viviendas de una o dos plantas como máximo, con huecos muy pequeños, con muros de mampostería blanqueados, donde la piedra queda con frecuencia vista, principalmente en la segunda planta. El granito es el gran protagonista, extendiéndose en líneas por la fachada o recercando los huecos, principalmente el de portada. Las jambas y dinteles suelen ser monolíticos y en ocasiones llevan relieves o incisiones con fechas, adornos o símbolos religiosos. En Añora se conservan calles enteras con fachadas de sillares de granito remarcados de blancas tiras y el casco histórico de Dos Torres, ha conservado a través de los siglos la tipología de la vivienda tradicional, con un alto valor patrimonial, lo que le ha supuesto la declaración como bien de interés cultural, con la categoría de conjunto histórico, con casas con artísticas portadas de remarcados dinteles y escudos heráldicos que reflejan la importancia de la villa en el pasado. 

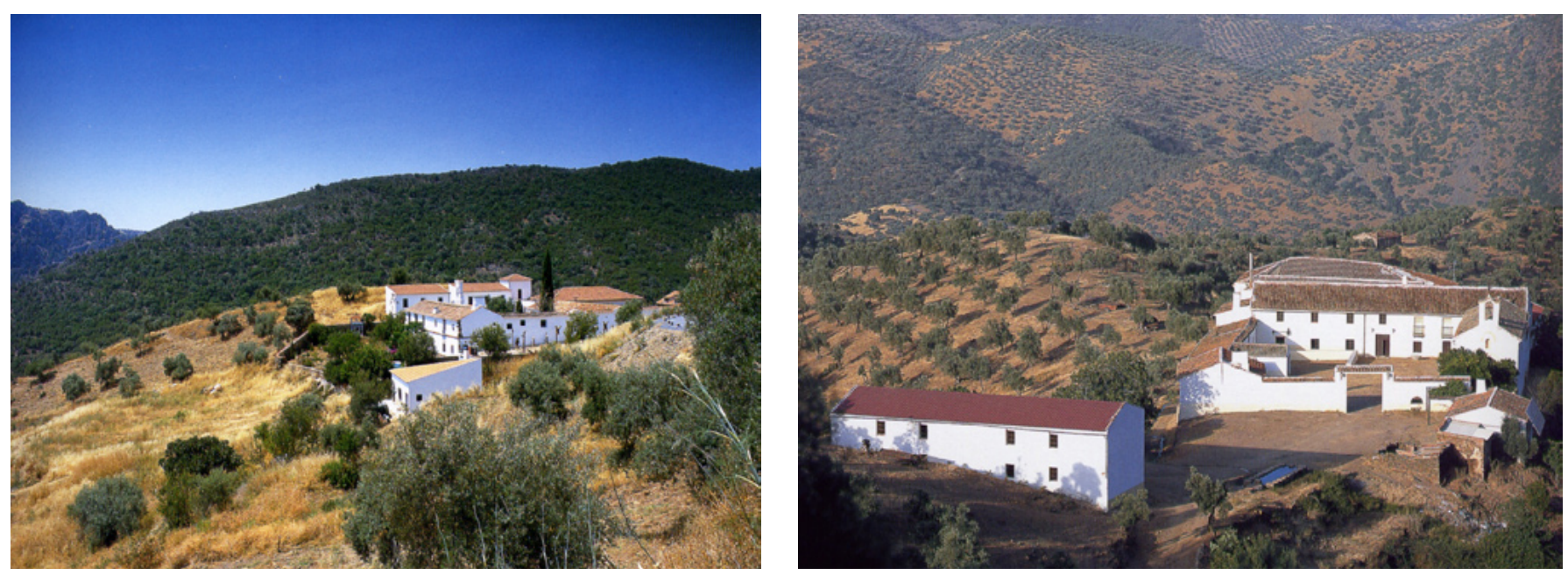

Pozoblanco. Cortijo de la Canaleja (izquierda) y cortijo de Pedrique (derecha) | fuente AA. VV., 2000

Asimismo, dada la actividad agropecuaria de la comarca, hay que hacer mención a la arquitectura agraria, que se adapta al carácter funcional y exigencias productivas de las explotaciones a las que se han vinculado los edificios. Al estar en uso muchas de estas explotaciones ha propiciado la conservación y la recuperación de un importante número de conjuntos, si bien en ocasiones se ha alterado su fisonomía primitiva. Por su carácter de penillanura aplanada por la erosión han predominado históricamente las formaciones de dehesa, con explotaciones ganaderas y de olivar. Entre los edificios más representativos cabe destacar El Pizarro en El Viso, Cantos Blancos en Belalcázar y Casa de la Barquera y Casilla Trapillos de las Monjas en Hinojosa del Duque, dedicadas principalmente a la explotación de ganado ovino (AA.VV., 2006: tomo I, p. 551).

En torno a los núcleos urbanos, y en especial en los términos de Pozoblanco, Dos Torres, Añora y Pedroche, con explotaciones intensivas de ganado vacuno, se han alterado profundamente las construcciones como se observa en El Escribano de Dos Torres o el Cortijo Barranco Serrano en Añora. Tras la ganadería tienen un papel muy importante los cultivos del olivar, localizándose sobre todo en los términos de Pozoblanco, Alcaraceños y Villanueva de Córdoba, entre los que destacan los cortijos de La Canaleja, La Aliseda o de Pedrique. Este último perteneció a una congregación de ermitaños del Yermo de Córdoba, de ahí que tenga mayor entidad y dimensiones que otros edificios vinculados a la explotación del olivar. Actualmente responde a una estructura cerrada formada por tres volúmenes edificados, dispuestos perpendicularmente a la fachada de acceso y articulados en torno a dos patios $y$ un jardín (AA.VV., 2006: tomo I, pp. 599 y ss.). El edificio está muy alterado al haberse habilitado como residencia sede de la Fundación Aurelio Teno, con un museo dedicado al artista cordobés. 


\section{BIBLIOGRAFÍA}

- AA.VV. (2006) Cortijos, haciendas y lagares: arquitectura de las grandes explotaciones agrarias de Andalucía: Provincia de Córdoba. Sevilla: Junta de Andalucía. Consejería de Obras Públicas y Transportes, 2006

- BANDA Y VARGAS, A. (1974) El arquitecto andaluz Hernán Ruiz II. Sevilla: Universidad de Sevilla, 1974

- BorRÁs GUALIS, G. M. (1990) El Islam. De Córdoba al mudéjar. Madrid: Silex, 1990

- CAMACHO mARTínez, R. (1986) Aportaciones al estudio de Hernán Ruiz III. Aptheca, n. ${ }^{\circ}$ 6, Córdoba, 1986

- FERNÁNDEZ GONZÁLEZ, R. (1969) El castillo de Belalcázar. B.R.A.C., n. ${ }^{\circ}$ 89, Córdoba, 1969

- JoRdANO BARBUdo, M. ${ }^{a}$ Á. (2013) Córdoba en el Camino Mozárabe de Santiago. El arte mudéjar, encuentro de culturas. En Actas II Congreso Internacional Camino Mozárabe de Santiago, Badajoz: CEDER "La Serena", 2013

- LEÓN MUÑOz, A. (2003) Las fortalezas de Belalcázar (Córdoba). Análisis arqueológico de su arquitectura (ss. IX-XIX). Córdoba: Publicaciones Universidad de Córdoba, 2003

- MÁRQUEZ TRIGUEROS, E. (1995) Iglesias medievales del Valle de los Pedroches. Córdoba: Grupo PRASA, 1995

- MOLINERO MERCHÁN, J. A. (2006) Iglesia parroquial de Nuestra Señora de la Asunción de Dos Torres. Córdoba: Ayto. Dos Torres, Diputación Provincial de Córdoba, 2006

- MOLINERO MERCHÁN, J. A. (2007) El convento de Santa Clara de la Columna de Belalcázar. Estudio HistóricoArtístico. Córdoba: Diputación Provincial de Córdoba, Delegación de Cultura 2007

- MOLINERO MERCHÁN, J. A. (2008) Villanueva del Duque. Patrimonio monumental y artístico. Córdoba: Ayto. Villanueva del Duque, 2008

- MOlinero MERChÁN, J. A. (2011) Palacio renacentista de Belalcázar. Humanismo del tercer Duque de Béjar. Córdoba: Servicio de publicaciones Universidad de Córdoba, 2011

- MORALES, A. J. (1996) Hernán Ruiz el Joven. Madrid: Akal, 1996

- MORENO VALERO, M. (2001) La vida tradicional en los Pedroches. Córdoba: M. Moreno, 2001

- NIETO CUMPLLIDO, M. (1982) Informe históricoartístico sobre la iglesia parroquial de San Juan Bautista de Hinojosa del Duque (Córdoba). Córdoba: Parroquia de San juan Bautista (Hinojosa del Duque), 1982
- OCAÑA TORREJÓN, J. (1973) El castillo de Santa Eufemia. B.R.A.C., n. ${ }^{\circ}$ 93, Córdoba, 1973

- VILLAR MOVELLÁN, A. (dir.) (1995) Guía artística de la provincia de Córdoba. Córdoba: Servicio de Publicaciones de la Universidad de Córdoba, 1995

- VILLAR MOVELLÁN, A.; DABRIO GONZÁLEZ, M. ${ }^{a}$ T.; RAYA RAYA, M. ${ }^{a}$ Á. (2006) Guía artística de Córdoba y su provincia. Córdoba: Ayuntamiento de Córdoba; Sevilla: Fundación José Manuel Lara, 2006 